\section{Herbicide critic dropped from pollution conference}

\author{
Rex Dalton, San Diego \\ A California biologist \\ is accusing Minnesota \\ officials of censorship \\ for blocking his \\ conference lecture \\ about environmental \\ damage associated \\ with a popular
}

agricultural herbicide.

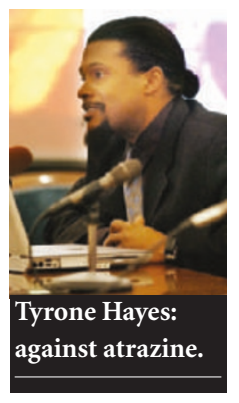

Tyrone Hayes of the

University of California, Berkeley, says the Minnesota Pollution Control Agency was succumbing to pressure from pro-industry government officials when, late last month, it withdrew an invitation for him to deliver the plenary talk at its Air, Water and Waste Conference next February.

Hayes has published extensively on links between low levels of exposure to the herbicide atrazine and developmental defects in amphibians. He also cites studies linking atrazine to prostate cancer and decreased sperm counts in men. Syngenta, the Swiss-based firm that makes the herbicide, says there is no evidence of environmental damage.

Last year, the Environmental Protection Agency (EPA) re-registered atrazine despite a regulatory review that drew flak from Hayes for relying on too many industry-funded studies. He repeated his criticism on 25 October at a hearing of a committee of Minnesota state representatives, who are considering banning the herbicide.

Sheryl Corrigan, the pollution agency's commissioner, said in a statement that she doubted whether Hayes's research "was the right focus" for the conference. She instructed her staff to withdraw their invitation.

Hayes says that agency officials first asked him to cut the word 'atrazine' from his talk, which he refused to do. He adds that they told him that an EPA official "instigated" the "uninvitation" by contacting officials at the Minnesota Department of Agriculture, who then contacted the pollution agency.

Agriculture officials acknowledged contacting the agency. EPA officials did not respond to interview requests.

After criticism from environmental groups, the pollution agency reinvited Hayes to give some form of lecture not a keynote address. But Hayes says he doubts he will attend, because Corrigan blocked her staff from listening to his testimony. Corrigan claims that limiting staff attendance at hearings is routine.

\title{
Hopes rise for RNA therapy as mouse study hits target
}

\section{Erika Check, Washington}

The efficacy of a promising therapeutic technique has been demonstrated in a study that might also relieve concerns about the approach's safety, researchers say.

Biologists at the company Alnylam Pharmaceuticals this week publish results showing that RNA interference - RNAi, for short - can lower cholesterol levels in mice (see page 173). The study is particularly encouraging because the treatment was injected directly into the bloodstream - a delivery method whose simplicity appeals to clinicians.

Human trials of RNAi, which aims to switch off disease-causing genes, have already begun for the eye disease macular degeneration. But these apply treatment directly to the eye. The Alnylam study, by introducing treatment through the bloodstream, could greatly increase the clinical value of RNAi, advocates say.

But RNAi specialists are also excited by aspects of the study that suggest the treatment did not interfere with genes other than those specifically targeted by the researchers. Experts in the field have been worried that the technique's clinical promise could run aground on unwanted 'off-target' effects. (A. L. Jackson and P. S. Linsley Trends Genet. 20, 521-524;2004).

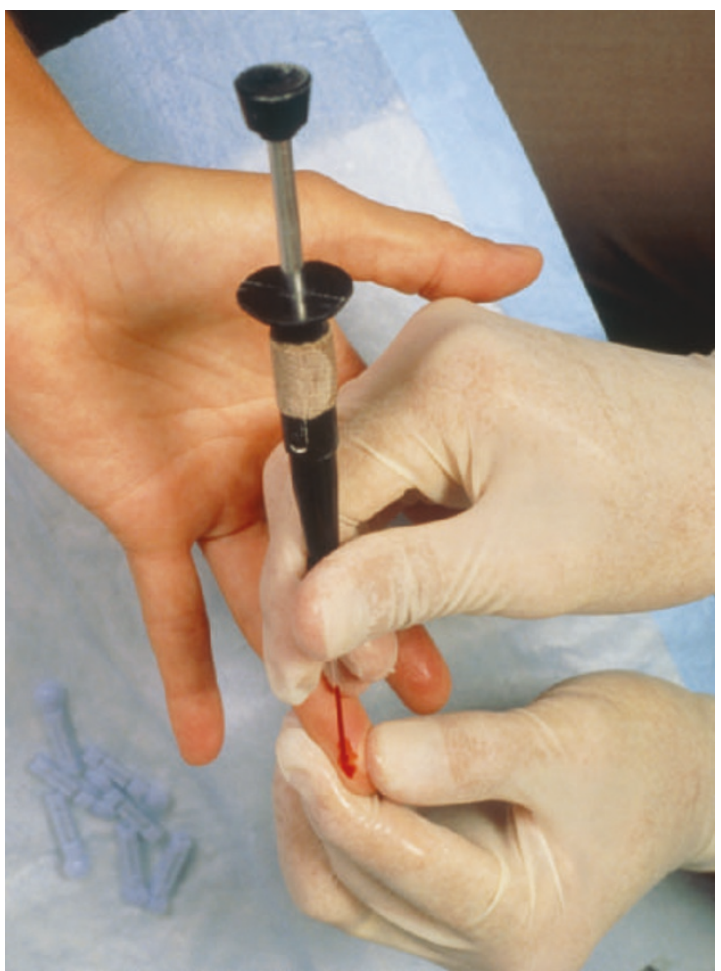

Prick of the bunch: trials of RNAi therapy in mice could lead to treatments for humans with high cholesterol levels.
In RNAi, a cell is made to destroy pieces of RNA instead of translating them into a protein. The cell can be triggered to destroy pieces of this genetic material that match a particular target sequence, rather than simply shutting off all RNAs. As a result, RNAi is a powerful tool for silencing specific genes.

But work published last year found that RNAi could also change expression of RNAs that closely resembled a target RNA — not just the target RNA itself (A. L. Jackson et al. Nature Biotechnol. 21, 635-637; 2003). Investigators have also found that RNAi can change the levels of proteins that are not related to the target RNA (P. C. Scacheri et al. Proc. Natl Acad. Sci. USA 101, 1892-1897; 2004).

The Alnylam researchers, most of whom are based at the company's laboratories in Kulmbach, Germany, investigated these effects by measuring the levels of RNA expressed by genes that were unrelated to their target gene. They found that the expression of the unrelated genes did not change during the experiment. They also proved that the therapeutic effect - an overall decrease of cholesterol levels in the blood - was due to an on-target effect, by showing that the target RNA was destroyed at the points they hoped to hit with their treatment molecule.

"We included all the appropriate controls explicitly because we wanted to address the concerns people would have about off-target effects," says John Maraganore, Alnylam's chief executive, based in Cambridge, Massachusetts. He adds that the group's demonstration of how the mechanism actually cut cholesterol levels is the most definitive proof yet that RNAi works the way it is predicted to in mammals.

But Aimee Jackson of Rosetta Inpharmatics, a bioinformatics company based in Seattle, Washington, points out that further questions need to be answered before the technique moves to the clinic. The Alnylam team only analysed a few off-target genes, and did not analyse levels of many proteins from different organs, so its results do not prove that no off-target effects occurred. The mice were also studied over a relatively short period of time. "We don't know if there are effects on other organs," says Jackson. 